\title{
Oriented Functionalization of Natural Hollow Kapok Fiber for Highly Efficient Removal of Toxic Hg(II) from Aqueous Solution
}

\author{
Feng Wang ${ }^{1,2}$, Yian Zheng ${ }^{1,3 *}$, Yongfeng Zhu ${ }^{1,2}$ and Aiqin Wang ${ }^{1 *}$ \\ ${ }^{1}$ Center of Eco-material and Green Chemistry, Lanzhou Institute of Chemical Physics, Chinese Academy of Science, \\ Lanzhou, China, ${ }^{2}$ University of the Chinese Academy of Sciences, Beijing, China, ${ }^{3}$ Gansu Key Laboratory for Environmental \\ Pollution Prediction and Control, College of Earth and Environmental Sciences, Lanzhou University, Lanzhou, China
}

\section{OPEN ACCESS}

Edited by:

Leonardo Fernandes Fraceto, São Paulo State University - Unesp,

Brazil

Reviewed by:

Daiana Avila,

Universidade Federal do Pampa,

Brazil

Renato Grillo,

International Iberian Nanotechnology Laboratory, Portugal

${ }^{*}$ Correspondence:

Yian Zheng

zhengya@|zu.edu.cn;

Aiqin Wang

aqwang@licp.cas.cn

Specialty section:

This article was submitted to Green and Environmental Chemistry, a section of the journal

Frontiers in Environmental Science

Received: 12 November 2015

Accepted: 13 January 2016

Published: 04 February 2016

Citation:

Wang $F$, Zheng $Y$, Zhu Y and Wang $A$ (2016) Oriented Functionalization of Natural Hollow Kapok Fiber for Highly Efficient Removal of Toxic Hg(II) from Aqueous Solution.

Front. Environ. Sci. 4:4.

doi: 10.3389/fenvs.2016.00004
Due to hollow and tubular structure, a natural kapok fiber (KF) was used as the support and orientation matrix to control the polymerization of ethyleneglycol dimethacrylate (EGDMA) and $N$-vinylimidazole (VIM) along its inherent axial surface via a facile in situ rapid polymerization reaction in air atmosphere. The as-formed KF@VIM/EGDMA composite is featured with porous surface and rich $N$-containing functional groups for potential application as a highly efficient adsorbent for removal of toxic $\mathrm{Hg}$ (II) from aqueous solution. The variables affecting the adsorption capacity were studied, including monomer ratio, external $\mathrm{pH}$ values, contact time, and initial $\mathrm{Hg}(\mathrm{II})$ concentration. The pseudo-second-order equation and two adsorption isotherms including Langmuir and Freundlich equations were applied to determine the adsorption kinetics and adsorption capacity. The results show that the as-prepared KF@VIM/EGDMA composite has a maximum adsorption capacity of $697 \mathrm{mg} / \mathrm{g}$ to $\mathrm{Hg}(\mathrm{II})$, while no appreciable adsorption capacity can be found for KF itself. Given its intrinsic large lumen, faster adsorption kinetics (45 min) are also expected and observed for KF@VIM/EGDMA. After a simple filtration, this adsorbent can be directly separated from the aqueous solution and then be regenerated for multi-cyclable utilization. During the adsorption process, the chemical complexing represents the main adsorption mechanism. As a naturally renewable KF, such a simple preparation method opens a new avenue to develop highly efficient and economically viable adsorbent for removal of toxic heavy metal from aqueous solution.

Keywords: kapok fiber, oriented, $\mathrm{N}$-vinylimidazole, selective adsorption, $\mathrm{Hg}(\mathrm{II})$

\section{INTRODUCTION}

Owing to high surface-to-mass ratio, bio-compatibility, good mechanical performance and ability to be shaped in various forms, many natural or man-made microfibers have been directly utilized or modified as an ideal substrate material for loading active nanoparticles (El Ghali et al., 2012; Xia et al., 2013). Among them, kapok fiber (KF) is obtained from the fruits of the kapok tree (Zheng et al., 2012), and is a kind of single-cell natural cellulose fiber with about $64 \%$ cellulose, $13 \%$ lignin, 2.5\% xylan, and $0.8 \%$ wax (Liu et al., 2012b). KF is the lightest, thinnest, and highest hollow degree material among the natural ecological fibers and exhibits fluffy, low density, non-allergic, non-toxic, better surface activity, good oil absorptivity, resistant to rot, and water-repellent nature 
(Lim and Huang, 2007; Liu et al., 2012b). Therefore, KF has been traditionally used as the stuffing for bedding, life preservers, upholstery, and water-safety equipment and for insulation against sound and heat (Liu et al., 2012b). Structured with rather fine natural microtubules (ca. $8-10 \mu \mathrm{m}$ in diameter and ca. $0.8-1.0 \mu \mathrm{m}$ in wall thickness) (Chung et al., 2008) with the hollow rate of above $86 \%$ (Kang et al., 2007), this fiber shows also its potential for various new application fields, especially as the support for active nanoparticles and as the biotemplate to prepare a series of microtubes originated from organic or inorganic materials (Zheng et al., 2014). KF is an insoluble natural polymer with a hollow and large lumen, and then it is anticipated to guide the growth orientation of a polymerizable monomer to avoid the agglomeration of polymer and enlarge the specific surface. Accordingly, the resulting KF composites can be easily separated or recovered from liquid system (Huang and Lim, 2006; Abdullah et al., 2010). Furthermore, the orientated growth of a polymerizable monomer on the surface of KF can afford the resulting material with tailored functional groups for promising application as an excellent adsorbent for removal of a targeted pollutant.

Mercury $(\mathrm{Hg})$ is one of the most hazardous heavy metals included on the US Environmental Protection Agency's (EPA) list of priority pollutants (Idris et al., 2011). Due to its persistence and bio-accumulation in the food chain (Shan et al., 2015), this metal is extremely harmful to both public health and aquatic life and thus, the removal of $\mathrm{Hg}$ (II) from aqueous solutions has attracted increasing attention. Adsorption is an important and useful technology for removal of heavy metal ions from aqueous solution and the core of this technology is to develop a novel kind of adsorbent. Up to date, this technology shows little/no selectivity in generally (Idris et al., 2011) and the large capital and high regeneration costs of adsorbent should also be stressed for wastewater treatment (Uğuzdoğan et al., 2009). Therefore, functional modification of abundant natural polymers in particular for those plant materials with metal chelating sites seems to be a useful method to overcome these problems (Zheng et al., 2014). One can speculate that KF may be a promising alternative for developing such a novel adsorbent with tailored functionality by modifying it by a polymer coating with high affinity to $\mathrm{Hg}(\mathrm{II})$.

As a kind of nitrogen-substituted aromatic heterocycle, $\mathrm{N}$-vinylimidazole (VIM) is considered to be one of the most favorable species with great chelating tendency for $\mathrm{Hg}$ (II) (Kara et al., 2005; Bessbousse et al., 2010). Sun et al. (2013) prepared a silica-based adsorbent by $\gamma$-radiation induced grafting of VIM on the silica arisen from chlorotrimethylsilane, and the adsorption capacity of the as-prepared adsorbent for $\mathrm{Hg}$ (II) was as high as $355.9 \mathrm{mg} / \mathrm{g}$ in $\mathrm{HgCl}_{2} / \mathrm{HNO}_{3}$ solution at $\mathrm{pH}$ 5. Shan et al. (2015) modified the $\mathrm{Fe}_{3} \mathrm{O}_{4} @ \mathrm{SiO}_{2}$ magnetic nanoparticles by grafting poly( $N$-vinylimidazole $)$ oligomer to fabricate an adsorbent (FSPV) to remove $\mathrm{Hg}$ (II) from water and found that the $\mathrm{Hg}$ (II) adsorption capacity of FSPV was $346 \mathrm{mg} / \mathrm{g}$ at $\mathrm{pH} 7$ and $25^{\circ} \mathrm{C}$ in $10 \mathrm{mM} \mathrm{NaCl}$. Thus, orientated growth of polymerizable VIM along the KF surface will be a feasible plan for developing an adsorbent with high affinity for $\mathrm{Hg}$ (II). Furthermore, the insolubility of $\mathrm{KF}$ enables the as-formed composite to be easily separated or recovered from liquid system. However, the existence of waxy coating on KF makes it hydrophobic, and accordingly, this fiber is gaining much attention as an alternative for oil removal (Ali et al., 2011; Wang et al., 2013a), but rarely in aqueous solution (Duan et al., 2013). Therefore, it is a prerequisite to change the wettability of $\mathrm{KF}$ from original hydrophobicity to hydrophilicity so as to remove pollutants from aqueous solution efficiently. It is reported that when $\mathrm{KF}$ was treated with sodium chlorite $\left(\mathrm{NaClO}_{2}\right)$ under acidic condition, the surface wax can be efficiently removed while its hollow lumen can be perfectly retained (Keshk et al., 2006; Kang et al., 2007).

Based on above background, KF used in this study can be firstly pre-treated with $\mathrm{NaClO}_{2}$ under acidic condition, and the treated KF can then be coated with VIM as the metal chelating sites, using ethyleneglycol dimethacrylate (EGDMA) as both of comonomer and crosslinker by a facile step to achieve a cheap adsorbent KF@VIM/EGDMA with efficient selectivity and high regeneration for $\mathrm{Hg}$ (II) removal. The specific objectives of this study are (i) optimization of the ratio of EGDMA to VIM and the amount of KF for preparation of the adsorbent; (ii) preparation of a fiber-like KF@VIM/EGDMA with unique morphology and easy separation or recovery ability from liquid system; and (iii) evaluation of the efficacy of the as-prepared KF@VIM/EGDMA composite for $\mathrm{Hg}(\mathrm{II})$ removal.

\section{EXPERIMENTAL METHODS}

\section{Materials}

KF was purchased from Shanghai Panda Co. Ltd., China. $N$-vinylimidazole (VIM, 99\%) was purchased from Alfa Aesar Chemical Co., Ltd., Tianjin, China. Ethylene glycol dimethacrylate (EGDMA, >97\%) was provided by Tokyo Chemical Industry Co., Ltd. 2,2'-azobis(2-methylpropionitrile) (AIBN, AR) was received from Tianjin Kaixin Chemical Industry Co., Ltd., China. Hydrochloric acid $(\mathrm{HCl})$, sodium hydroxide $(\mathrm{NaOH})$ and other reagents used were all analytical-reagent grade. Deionized water was used throughout the experiments. All of above reagents were used without further purification.

\section{Kapok Fiber Treated by $\mathrm{NaClO}_{2}$}

Kapok fiber $(1.5 \mathrm{~g})$ was pre-treated with $100 \mathrm{~mL}$ of the mixture solution of $\mathrm{NaClO}_{2}(0.93 \mathrm{~g})$ and glacial acetic acid $(1.42 \mathrm{~mL})$ at $90^{\circ} \mathrm{C}$ for $1 \mathrm{~h}$. The treated $\mathrm{KF}$ was washed with distilled water until the filtrate reached $\mathrm{pH} 6-7$, then dried at $70^{\circ} \mathrm{C}$ to a constant weight. The treated KF was whiter than the pristine one as a result of bleaching property of $\mathrm{NaClO}_{2}$.

\section{Preparation of Poly(N-vinylimidazole-Co-Ethylene Glycol Dimethacrylate)}

For the preparation of poly(N-vinylimidazole-co-ethylene glycol dimethacrylate) (P(VIM-co-EGDMA)) with high affinity to $\mathrm{Hg}(\mathrm{II})$, the monomer ratio of EGDMA to VIM was firstly optimized according to the following procedure (Table S1): a designed amount of EGDMA and VIM ( $2 \mathrm{~g}$ ) were dissolved into $10 \mathrm{ml}$ methanol using $0.08 \mathrm{~g}$ AIBN as the initiator for free-radical 
polymerization. After the reactions were proceeded in an oven at $60^{\circ} \mathrm{C}$ for $24 \mathrm{~h}$ to obtain some white powder, the resulting products were washed with distilled water and centrifugated for several times, and then dried at $40^{\circ} \mathrm{C}$ in an oven to a constant weight.

\section{Preparation of KF@VIM/EGDMA Composites}

According to the optimization condition of Section Preparation of Poly(N-vinylimidazole-Co-Ethylene Glycol Dimethacrylate), a series of KF-based composite adsorbents were prepared by the following procedure: A predetermined amount of KF (Table 1) was added into $5 \mathrm{~mL}$ of methanol containing $0.75 \mathrm{~g}$ EGDMA, $1.0 \mathrm{~g}$ VIM and $0.04 \mathrm{~g}$ AIBN, then the reaction was performed in an oven under $60^{\circ} \mathrm{C}$ for $24 \mathrm{~h}$ to obtain the products. After the reaction was finished, the resulting adsorbents were washed with distilled water for several times, filtered with a normal sieve and dried at $40^{\circ} \mathrm{C}$ in an oven to a constant weight. Scheme 1 showed the schematic diagram of the structure and formation of KF@VIM/EGDMA.

\section{Characterizations}

The surface morphology was observed using a field emission scanning electron microscope (FESEM, JSM-6701F, JEOL) after coating the samples with gold film. FTIR spectra of samples were recorded on a Thermo Nicolet NEXUS spectrometer in $4000-400 \mathrm{~cm}^{-1}$ wavenumber region using $\mathrm{KBr}$ pellets, with a $\mathrm{KBr}$ :sample ratio of 100:1. XRD patterns were collected on a X'pert PRO X-ray power diffractometer (PAN analytical Co., Netherlands) using $\mathrm{Cu}-\mathrm{K}_{\alpha}$ radiation of $1.5406 \AA(40 \mathrm{kV}, 30 \mathrm{~mA})$. X-ray photoelectron spectroscopy (XPS) was recorded on a PHI 5702 spectrometer equipped with a monochromatic Al Ka X-ray source. Thermogravimetry (TG) analysis of the samples was recorded by a Diamond TG-DTA 6300 thermoanalyzer instrument from 30 to $800^{\circ} \mathrm{C}$ at a heating rate of $10^{\circ} \mathrm{C} \mathrm{min}^{-1}$ under a nitrogen atmosphere.

The point of zero charge $\left(\mathrm{pH}_{\mathrm{PZC}}\right)$ was measured by an immersion technology according to the following process (Bourikas et al., 2003): adjusting the series aqueous solutions with varying $\mathrm{pH}$ values by adding 0.1 and $1.0 \mathrm{~mol} / \mathrm{L} \mathrm{HCl}$ or $\mathrm{NaOH}$ solutions, and then suspending $50 \mathrm{mg}$ adsorbent sample in the solutions. The aqueous suspensions were equilibrated for $24 \mathrm{~h}$ to reach an equilibrium $\mathrm{pH}$ value, and then the $\mathrm{pH}$ value of each suspension was measured with a digital $\mathrm{pH}$ meter (MettlerToledo, FE20). The $\triangle \mathrm{pH}$ was then determined from the $\mathrm{pH}$ change between the solution without and with the adsorbent, i.e., $\triangle \mathrm{pH}=\mathrm{pH}$ (blank solution) - $\mathrm{pH}$ (suspension). The $\mathrm{pH}_{\mathrm{PZC}}$ was identified as the $\mathrm{pH}$ where the minimum $\triangle \mathrm{pH}$-value was obtained. The zeta potentials were obtained by injecting the

TABLE 1 | Formulation for KF@VIM/EGDMA dispersion.

\begin{tabular}{lccccc}
\hline Serial number & $\mathbf{1}$ & $\mathbf{2}$ & $\mathbf{3}$ & $\mathbf{4}$ & $\mathbf{5}$ \\
\hline $\mathrm{KF}(\mathrm{g})$ & 0 & 0.3 & 0.4 & 0.5 & 0.6
\end{tabular}

suspension into the electrophoresis cell and measuring them with a Malvern Zetasizer Nano-ZS apparatus.

\section{Adsorption Experiments}

The batch adsorption experiments were carried out to evaluate the adsorption capacity of KF@VIM/EGDMA. Adsorption experiments were carried out by dispersing $20 \mathrm{mg}$ of adsorbent into $25 \mathrm{~mL}$ of heavy metal solutions in a thermostatic shaker (THZ-98A, Chincan, Zhejiang, China) at $30^{\circ} \mathrm{C}$ and $130 \mathrm{rpm}$ for a given time to achieve the adsorption equilibrium. After filtration, all the supernatant was left for further analysis to obtain the corresponding adsorption capacity. The concentrations of heavy metal ions in the solution were measured by ultraviolet spectrophotometry with a Specord 200UV/vis spectrophotometer at the maximum absorbency wavelength (456 nm for $\mathrm{Cu}^{2+}, 550 \mathrm{~nm}$ for $\mathrm{Pb}^{2+}, 582 \mathrm{~nm}$ for $\mathrm{Cd}^{2+}, 548 \mathrm{~nm}$ for $\mathrm{Zn}^{2+}$, and $558 \mathrm{~nm}$ for $\mathrm{Hg}$ (II) using 2,9-dimethyl-1,10phenanthroline (for $\mathrm{Cu}^{2+}$ ), xylenol orange (for $\mathrm{Pb}^{2+}$ and $\mathrm{Cd}^{2+}$ ), 1-(2-pyridylazo)-2-naphthol (for $\mathrm{Zn}^{2+}$ ) and safranine $\mathrm{T}$ (for $\mathrm{Hg}(\mathrm{II}))$ as the respective complexing agents. The amount of heavy metal ions adsorbed ( $q, \mathrm{mg} / \mathrm{g}$ ) was calculated according to the following formulas:

$$
q=\frac{\left(C_{0}-C_{\mathrm{e}}\right) \times 0.025}{m}
$$

Here, $q$ is the amount of metal ion adsorbed at equilibrium $(\mathrm{mg} / \mathrm{g}), C_{0}(\mathrm{mg} / \mathrm{L})$ is the initial concentration, $C_{\mathrm{e}}(\mathrm{mg} / \mathrm{L})$ is the equilibrium concentration $(\mathrm{mg} / \mathrm{L}), 0.025$ is the volume of the adsorbate solution (L), and $m$ is the mass of the adsorbent used (g). All of these experiments were carried out in triplicate to assure the results were reproducible, and the relative standard deviation was less than $5 \%$ in this study.

The $\mathrm{HgCl}_{2}$ solution with initial concentration of $300 \mathrm{mg} / \mathrm{L}$ was used to evaluate the adsorption capacity of the series P(VIMco-EGDMA) and KF@VIM/EGDMA adsorbents to optimize the monomer ratio of EGDMA to VIM and the amount of KF. For the KF@VIM/EGDMA composite, selective adsorption was performed under non-competitive conditions by using single $\mathrm{CuCl}_{2}, \mathrm{PbCl}_{2}, \mathrm{ZnCl}_{2}, \mathrm{CdCl}_{2}, \mathrm{HgCl}_{2}$ solution with each concentration of $300 \mathrm{mg} / \mathrm{L}$ as the model. The required $\mathrm{pH}$ of solution was adjusted by $0.1 \mathrm{~mol} / \mathrm{L} \mathrm{NaOH}$ and $\mathrm{HCl}$ solutions. Batch adsorption experiments were carried out with a freshly prepared $\mathrm{HgCl}_{2}$ solution with an initial concentration of $400 \mathrm{mg} / \mathrm{L}$ at different contact time to study the adsorption kinetic. The adsorption capacity of $\mathrm{Hg}$ (II) onto KF@VIM/EGDMA was determined using an increasing concentration from 100 to $1000 \mathrm{mg} / \mathrm{L}$.

In order to evaluate the reusability, the influences of different desorbing agent and desorbing agent concentration on desorption efficiency were firstly studied to figure out the optimum desorption conditions. Firstly, $0.5 \mathrm{~mol} / \mathrm{L} \mathrm{H}_{2} \mathrm{SO}_{4}$, thiourea, $\mathrm{HCl}$ and $\mathrm{KI}$ solution were used as the desorption media. Then the effects of initial concentration of a chosen desorption medium on the desorption efficiency were evaluated. After that, the following procedures were performed to study the reusability of the as-prepared adsorbent: $20 \mathrm{mg}$ adsorbent was mixed with 


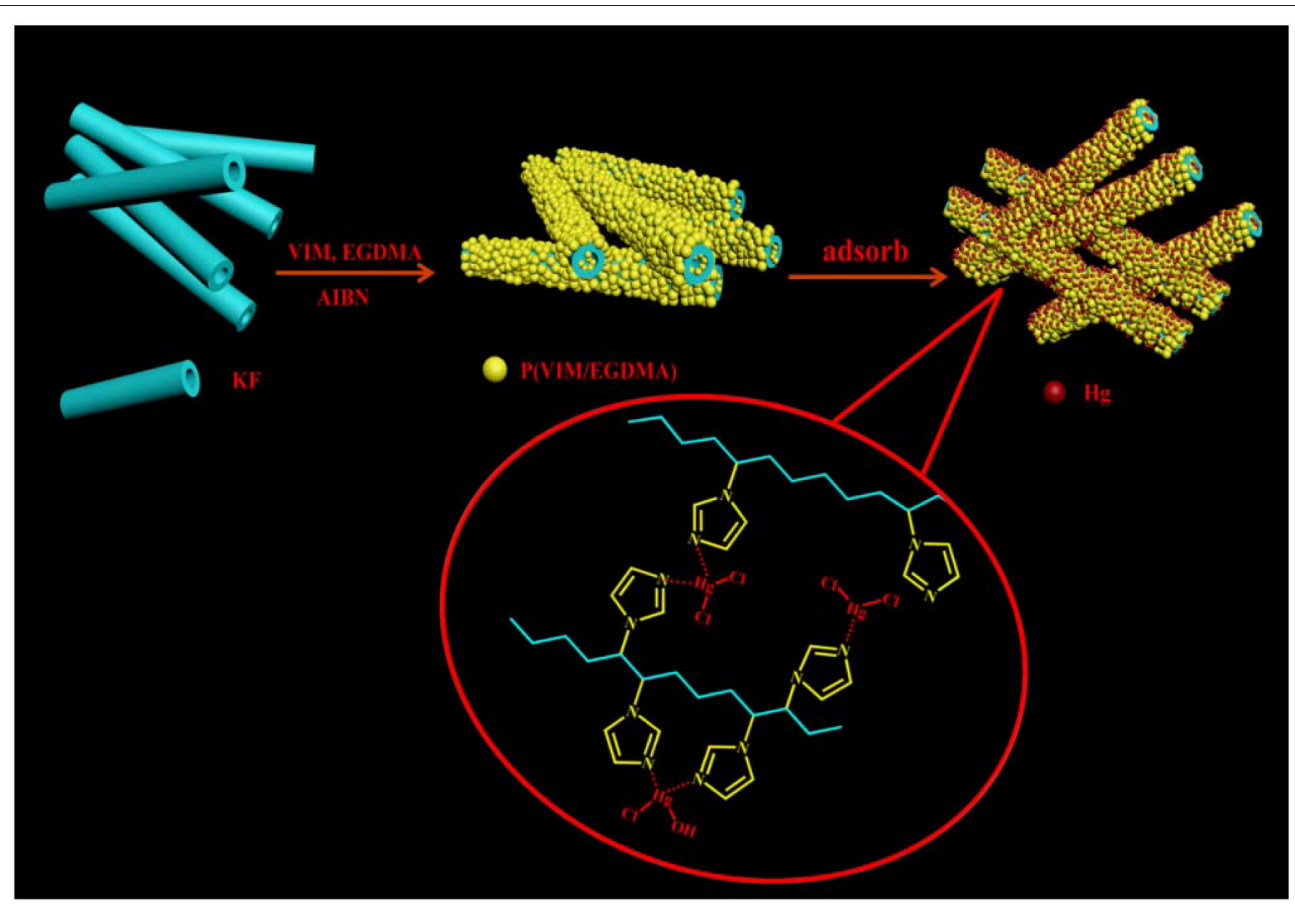

SCHEME 1 | The representation of a possible structure of KF@VIM/EGDMA and its adsorption for $\mathrm{Hg}(\mathrm{II})$.

$25 \mathrm{~mL} \mathrm{HgCl}_{2}$ solution ( $300 \mathrm{mg} / \mathrm{L}$ ) for $2 \mathrm{~h}$. After the adsorption equilibrium, the KF@VIM/EGDMA was desorbed with $25 \mathrm{~mL}$ chosen desorbing agent solution for $5 \mathrm{~h}$. Before the next cycle, the adsorbent was filtered and washed with distilled water for several times, and was neutralized with $\mathrm{NaOH}$ solution for $10 \mathrm{~min}$, then washed with distilled water till the $\mathrm{pH}$ reached about 5.5. The consecutive adsorption-desorption process was performed for seven times to test the reusability of the composite.

\section{Isotherm and Kinetics Models}

The models of Langmuir (Equation 2) and Freundlich (Equation 3) were used to fit the isotherm equations to the experimental data and calculate the theoretical maximum adsorption capacity (Alila and Boufi, 2009).

$$
\text { Langmuir equation: } \frac{C_{\mathrm{e}}}{q_{\mathrm{e}}}=\frac{1}{q_{\mathrm{m}} b}+\frac{C_{\mathrm{e}}}{q_{\mathrm{m}}}
$$

Freundlich equation: $\quad \log q_{\mathrm{e}}=\log K+(1 / n) \log C_{\mathrm{e}}$

Here $C_{\mathrm{e}}(\mathrm{mg} / \mathrm{L})$ is the equilibrium concentration of $\mathrm{Hg}(\mathrm{II}), q_{\mathrm{e}}$ ( $\mathrm{mg} / \mathrm{g})$ is the equilibrium adsorption capacity, and $q_{\mathrm{m}}(\mathrm{mg} / \mathrm{g})$ is the theoretical maximum value of adsorption capacity, $b(\mathrm{~L} / \mathrm{g})$ is the Langmuir adsorption constant representing the free energy of adsorption. $n$ (dimensionless) and $K(\mathrm{~L} / \mathrm{g})$ are the heterogeneity factor and the Freundlich isotherm constant, respectively. $1 / n$ indicates the bond distribution and $K$ represents the strength of the adsorptive bond related to the adsorption capacity.

Among various established kinetic models, the pseudo-firstorder (Equation 4) and pseudo-second-order (Equation 5) kinetic models are considered as the most commonly used models to investigate the mechanism ruling the adsorption process and quantify the changes in adsorption with time (Oo et al., 2009).

$$
\text { Pseudo-first-order: } \quad \log \left(q_{\mathrm{e}}-q_{\mathrm{t}}\right)=\log q_{\mathrm{e}}-\left(\frac{k_{1}}{2.303}\right) t
$$

$$
\text { Pseudo-second-order: } \frac{t}{q_{\mathrm{t}}}=\frac{1}{\left(k_{2} \times q_{\mathrm{e}}^{2}\right)}+\frac{t}{q_{\mathrm{e}}}
$$

Here $q_{\mathrm{t}}$ and $q_{\mathrm{e}}$ are the adsorption capacities of the adsorbent at time $t(\mathrm{~s})$ and at equilibrium, respectively. $k_{1}\left(\mathrm{~min}^{-1}\right)$ and $k_{2}(\mathrm{~g} / \mathrm{mg} \mathrm{min})$ are the rate constants of the pseudo-firstorder equation and pseudo-second-order equation, respectively. Kinetic constants $k$ and $q_{\mathrm{e}}$ were calculated from the slopes and intercepts of the plots of $\log \left(q_{\mathrm{e}}-q_{\mathrm{t}}\right)$ vs. $t$ and $t / q_{\mathrm{t}} \mathrm{vs} . t$, respectively.

\section{RESULTS AND DISCUSSION}

\section{Formation of KF@VIM/EGDMA}

During the formation of KF@VIM/EGDMA, the involved reaction mechanism is a typical free radical polymerization. When the temperature reached $60^{\circ} \mathrm{C}$, the initiator AIBN was decomposed to produce a radical which can initiate the polymerization. At the same time, the P(VIM-co-EGDMA) particles were formed in the dispersion and deposited on the fiber surface (Fan et al., 2012). With the proceeding of polymerization reaction, the surface of KF was coated by a thin layer of polymer coating consisted of P(VIM-co-EGDMA), as shown in Scheme 1. 


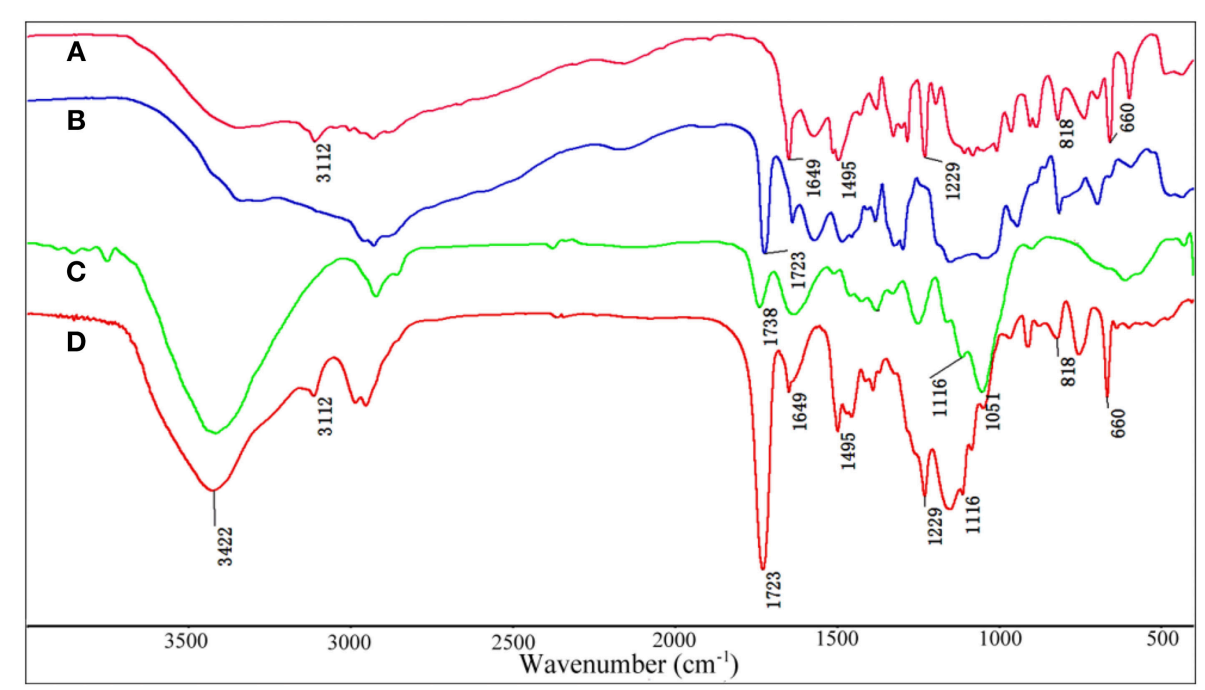

FIGURE 1 | FTIR spectra of (A) VIM, (B) EGDMA, (C) KF and (D) KF@VIM/EGDMA.

The point of zero charge $\left(\mathrm{pH}_{\mathrm{PZC}}\right)$ and isoelectric point $\left(\mathrm{pH}_{\mathrm{IEP}}\right)$ were measured by immersion technique and zeta potential measurements to understand the formation of adsorbent better. As shown in Figure S1, the $\mathrm{pH}_{\mathrm{PZC}}$ is 7.7 for KF@VIM/EGDMA and 7.2 for P(VIM-co-EGDMA), while the $\mathrm{pH}_{\text {IEP }}$ is 7.8 for KF@VIM/EGDMA and 8.4 for $\mathrm{P}$ (VIM-coEGDMA). The difference between $\mathrm{pH}_{\mathrm{PZC}}$ and $\mathrm{pH}_{\mathrm{IEP}}$ would give an indication of the surface charge distribution of the adsorbents. Compared the $\mathrm{pH}_{\text {IEP }}$ with $\mathrm{pH}$ PZC, the equal value of them would indicate the similar positively charged external surface and the interior of KF@VIM/EGDMA, suggesting that the inner wall of $\mathrm{KF}$ was also coated with polymer layer. In addition, the $\mathrm{pH}_{\mathrm{PZC}}$

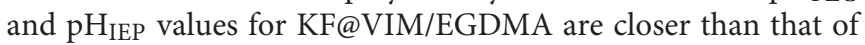
$\mathrm{P}$ (VIM-co-EGDMA), suggesting a more homogeneous surface of KF@VIM/EGDMA (Strelko Jr et al., 2002).

\section{FTIR Analysis}

The FTIR spectra of VIM (Figure 1A), EGDMA (Figure 1B), KF (Figure 1C), and KF@VIM/EGDMA (Figure 1D) are shown in Figure 1. The FTIR spectrum of KF@VIM/EGDMA (Figure 1D) is similar to that of KF (Figure 1C) except several characteristic absorption bands originated from VIM (Figure 1A) and EGDMA (Figure 1B). The broad band of KF at about $3422 \mathrm{~cm}^{-1}$ derived from the stretching vibration of $\mathrm{O}-\mathrm{H}$ in cellulose had almost no change after modification. The ester bands of $\mathrm{KF}$ at $1738 \mathrm{~cm}^{-1}$ which was ascribed to the vibration of $\mathrm{C}=\mathrm{O}$ was merged with the other carbonyl bond at $1723 \mathrm{~cm}^{-1}$ of EGDMA to create a strong and sharp absorption band in KF@VIM/EGDMA spectrum at $1723 \mathrm{~cm}^{-1}$. The absorption bands at $3112 \mathrm{~cm}^{-1}$ in the spectrum of KF@VIM/EGDMA was assigned as the stretching vibration of the $=\mathrm{CH}$ in the ring of VIM (Sun et al., 2013), and the narrow peak at $1229 \mathrm{~cm}^{-1}$ was ascribed to chain $\mathrm{C}-\mathrm{H}$ bending with $\mathrm{C}=\mathrm{N}$ stretching of imidazole (Talu et al., 2015). The band observed at $1495 \mathrm{~cm}^{-1}$ (Figures 1A,D) was assigned to the $\mathrm{C}-\mathrm{H}$ bending vibrations of the aliphatic chain in coupling with the $\mathrm{C}-\mathrm{C}$ and $\mathrm{C}=\mathrm{N}$ ring stretching vibrations of VIM (Sun et al., 2013). Furthermore, the narrow band at $1649 \mathrm{~cm}^{-1}$ in VIM spectrum which attributed to the characteristic of $\mathrm{C}=\mathrm{C}$ stretching vibration and the characteristic band of puckering vibration of imidazole ring at $660 \mathrm{~cm}^{-1}$ were also appeared in the KF@VIM/EGDMA spectrum. The characteristic absorption bands of VIM and EGDMA appeared in the FTIR spectrum of KF@VIM/EGDMA confirm that KF is combined successfully with polymers.

\section{SEM Morphology}

The photographs of the raw and modified KF presented in Figures 2A,B show that the raw KF is coated with polymer successfully and the as-prepared adsorbent has a fibrous shape. The FE-SEM images show that the raw KF presents regular hollow tubular structure with a smooth surface (Figure 2C). After being modified, both of external surface and inner wall are all covered with plenty of highly aggregated polymer particles with rough surface (Figures 2 D-F). Therefore, it can be concluded that KF can provide a wonderful substrate material to orient the growth of polymerizable monomers to form the KF@VIM/EGDMA fiber with amazing microstructure.

\section{XRD Analysis}

The crystalline structures of the native and the modified KF were also investigated by means of XRD technology. As can be seen from Figure 3A, the characteristic diffraction peaks of KF appear at $2 \theta$ of $15.78^{\circ}, 22.62^{\circ}$, and $34.96^{\circ}$, which correspond to the (110), (200) and (004) crystallogrphic planes, respectively (Liu et al., 2012a). Otherwise, the XRD pattern of KF@VIM/EGDMA (Figure 3B) shows significant changes in the crystalline peaks. The diffraction peak of KF at $2 \theta$ of $34.96^{\circ}(004)$ has disappeared and the intensity of diffraction peak at $2 \theta$ of $22.62^{\circ}(200)$ gets weaker, indicating that the aggregating crystalline phase has been 


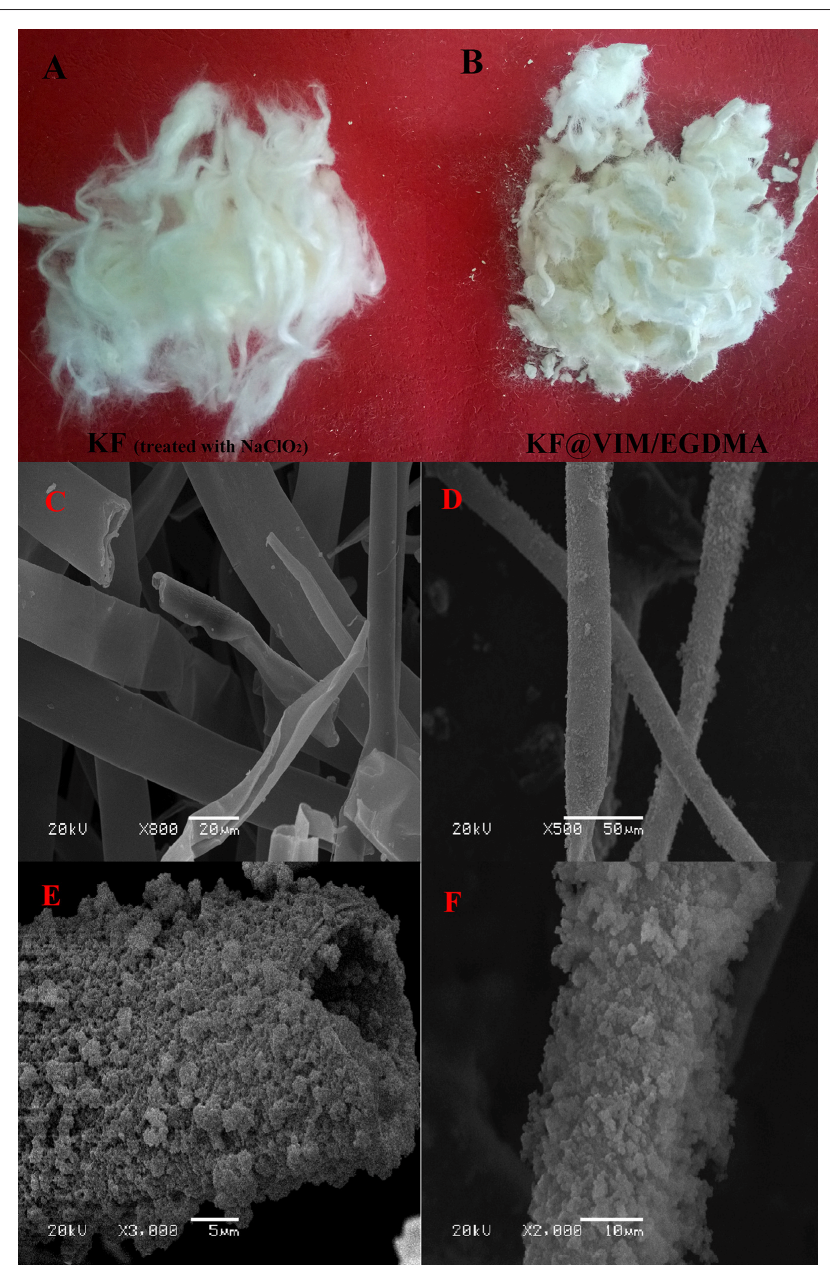

FIGURE 2 | Photographs of the treated KF (A) and KF@VIM/EGDMA (B) and SEM image of the KF (C) and KF@VIM/EGDMA (D-F).

greatly altered after modification. The XRD data indicate that KF is favorable to the attachment of polymer.

\section{TG Analysis}

Thermal analysis was performed to analyze the decomposition temperature and thermal stability of materials. The thermograms of the raw KF and KF@VIM/EGDMA are presented in Figure 4. The thermograms of $\mathrm{KF}$ and its composites showed the first weight loss at around $30-250^{\circ} \mathrm{C}$. This was due to the evaporation of water (Prachayawarakorn et al., 2013). The sudden steep weight losses of KF (Figure 4A) started at $242^{\circ} \mathrm{C}$ and ended around $364^{\circ} \mathrm{C}$ with almost $70 \%$ weight loss. Then a slow degradation started below $364^{\circ} \mathrm{C}$ and ended at $619^{\circ} \mathrm{C}$ with a little weight loss of 19\%. For the KF@VIM/EGDMA (Figure 4B), the thermogravimetry curve resembles apparently to that of KF. The maximum weight loss was occurred approximately at $269^{\circ} \mathrm{C}$ and ended near $411^{\circ} \mathrm{C}$ with an accompanying $51 \%$ weight loss. Then the followed degradation started from about 411 to $770^{\circ} \mathrm{C}$. The results of thermal analysis suggested that the thermal stability of the KF@VIM/EGDMA composite was improved.

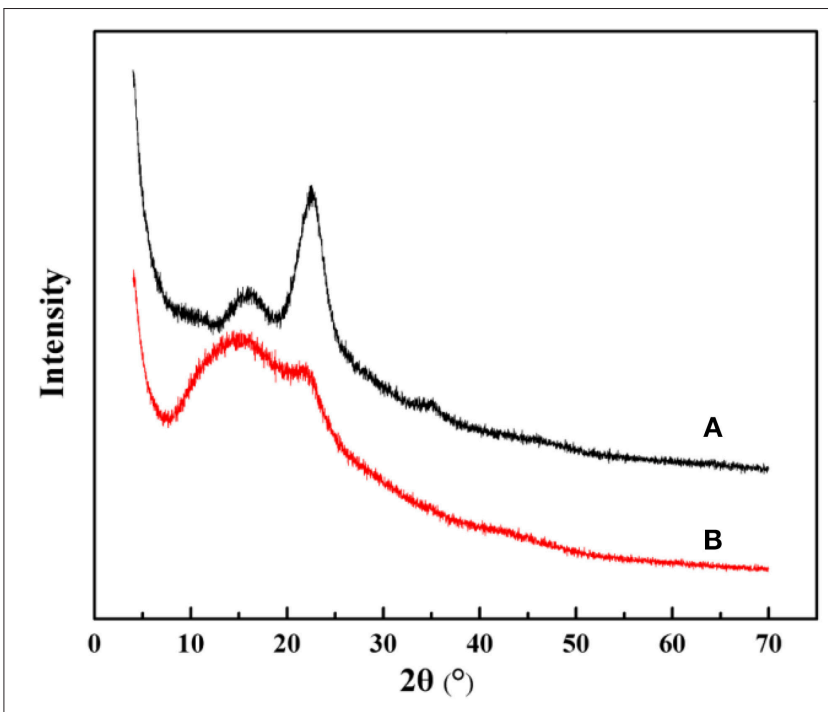

FIGURE 3 | XRD spectra of (A) KF and (B) KF@VIM/EGDMA.

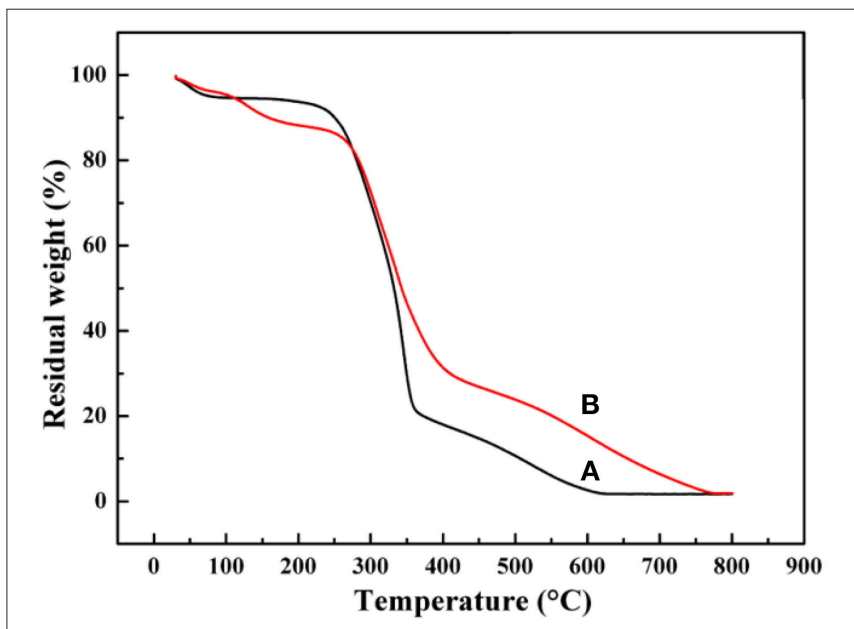

FIGURE 4 | TGA thermograms of (A) KF and (B) KF@VIM/EGDMA.

\section{Effect of Monomer Ratio on Adsorption Capacity}

The effects of EGDMA to VIM ratio on the adsorption capacity were investigated in Figure 5. It is clear that the adsorption capacities increased from 248.52 to $342.02 \mathrm{mg} / \mathrm{g}$ as the ratio of EGDMA to VIM was ranged from 3/2 (VIM\%: 40.0\%) to 1.5/2 (VIM\%: 57.1\%), beyond which the adsorption capacities showed a monotonic decrease. In general, increasing the VIM content is beneficial for the adsorption capacities, while excess VIM will result in a reduction in the adsorption capacity. The falling adsorption capacities of the adsorbent can be attributed to increasing steric hindrance of the imidazole ring as the VIM content increased. The large amount of VIM would impede the grafting of VIM, and accordingly, the adsorption capacity will be affected. This fact can be further testified by the decreasing yield. According to the results presented in Figure 5, the sample 
with EGDMA/VIM ratio of 1.5/2 was adopted for further investigation.

\section{Optimization of the Content of KF}

There is no doubt that the content of KF will influence the adsorption properties significantly. As shown in Figure 6A, KF shows no appreciable adsorption for $\mathrm{Hg}$ (II). Therefore, it is not surprising that with increasing amount of KF, KF@VIM/EGDMA exhibits a decreasing adsorption capacity for $\mathrm{Hg}$ (II) (Zheng et al., 2012). Otherwise, too much KF will result in insufficiency use of $\mathrm{KF}$ and cause unnecessary waste, while too little amount of KF is insufficient to orientate the growth of polymers onto its surface. Thus, $0.3 \mathrm{~g}$ KF was finally selected for further studies.

\section{Selective Adsorption of $\mathbf{H g}(\mathrm{II})$}

The selective adsorption results of KF@VIM/EGDMA are summarized in Figure 6B. It was found that the adsorption

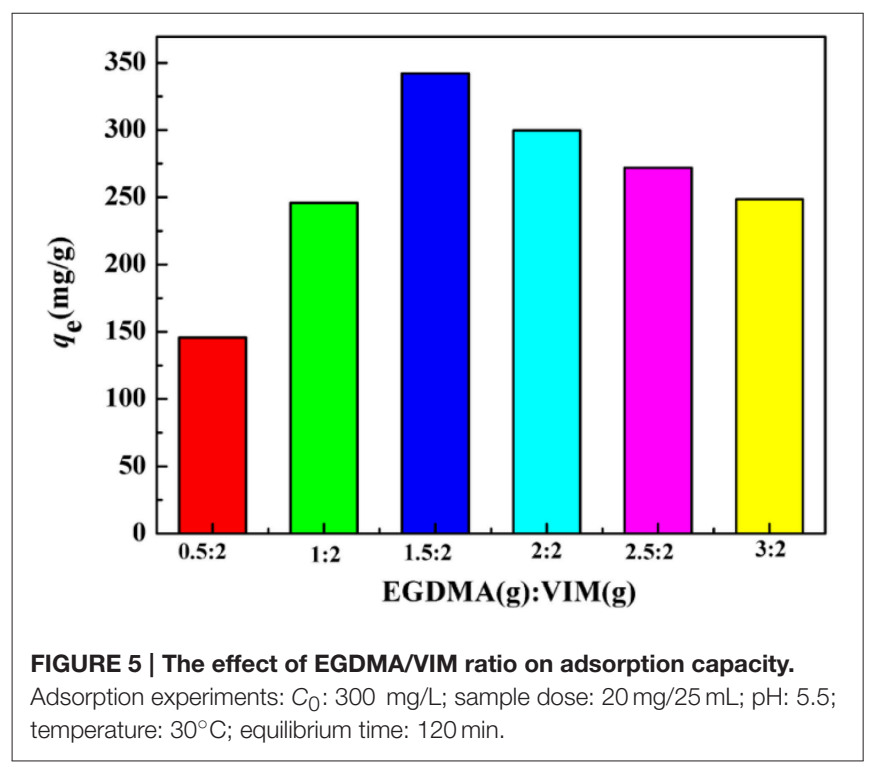

capacity for $\mathrm{Hg}(\mathrm{II})(286.20 \mathrm{mg} / \mathrm{g})$ was much higher than the other four heavy metals [Cu(II) $(32.12 \mathrm{mg} / \mathrm{g}), \mathrm{Pb}$ (II) $(20.08 \mathrm{mg} / \mathrm{g})$, $\mathrm{Cd}$ (II) $(17.47 \mathrm{mg} / \mathrm{g})$ and $\mathrm{Zn}$ (II) $(22.67 \mathrm{mg} / \mathrm{g})]$, indicating that the as-prepared adsorbent exhibited obvious adsorption selectivity to $\mathrm{Hg}$ (II) due to different metal ion species between $\mathrm{Hg}$ (II) and the others in the aqueous solutions. Compared with ionic heavy metals, the major species of $\mathrm{Hg}$ (II) in the solution was present in the form of electroneutral species such as $\mathrm{HgCl}_{2}$ and $\mathrm{HgClOH}$ that could promote the combination between $\mathrm{Hg}$ (II) and protonated imidazole ring to form the mercury-imidazole complex (Sun et al., 2013). The positive zeta potential values of KF@VIM/EGDMA at pH $<7$ in aqueous solution (Figure S1) could explain the selectivity of the adsorbent for $\mathrm{Hg}$ (II) very well. Furthermore, the interaction between $\mathrm{Hg}$ (II) and imidazole ring did not break the $\mathrm{Hg}-\mathrm{Cl}$ bond in $\mathrm{HgCl}_{2}$ and $\mathrm{HgClOH}$. All the information implies that the $\mathrm{Hg}(\mathrm{II})$ could be absorbed by KF@VIM/EGDMA via non-electrostatic forces (Shan et al., 2015).

\section{Effect of pH}

In general, the $\mathrm{pH}$ value has been considered as a significant parameter governing the extent of metal ion adsorption by an adsorbent as it influences both the surface properties of the adsorbent molecule (Shen et al., 2013; Kyzas et al., 2014), metal species and the availability of binding site of the adsorbate which depends on the functional group of an adsorbent (Afkhami et al., 2010). Since the metal species are mainly in the forms of precipitation at higher $\mathrm{pH}$ (Kampalanonwat and Supaphol, 2014), so the adsorption experiments were carried out at the initial $\mathrm{pH}$ range from 1 to 6 with initial concentration of 200 and $500 \mathrm{mg} / \mathrm{L}$ to avoid the precipitation.

As the results shown in Figure 7, the adsorption capacities remarkably increase with increasing initial $\mathrm{pH}$ at the highly acidic condition $(\mathrm{pH}<4.0)$ and obtained the maximum metal uptakes at close to neutral condition $(\mathrm{pH}=4-6)$. The adsorption capacities could largely be affected by the competitive interaction between metal and hydrogen ions with the active sites on
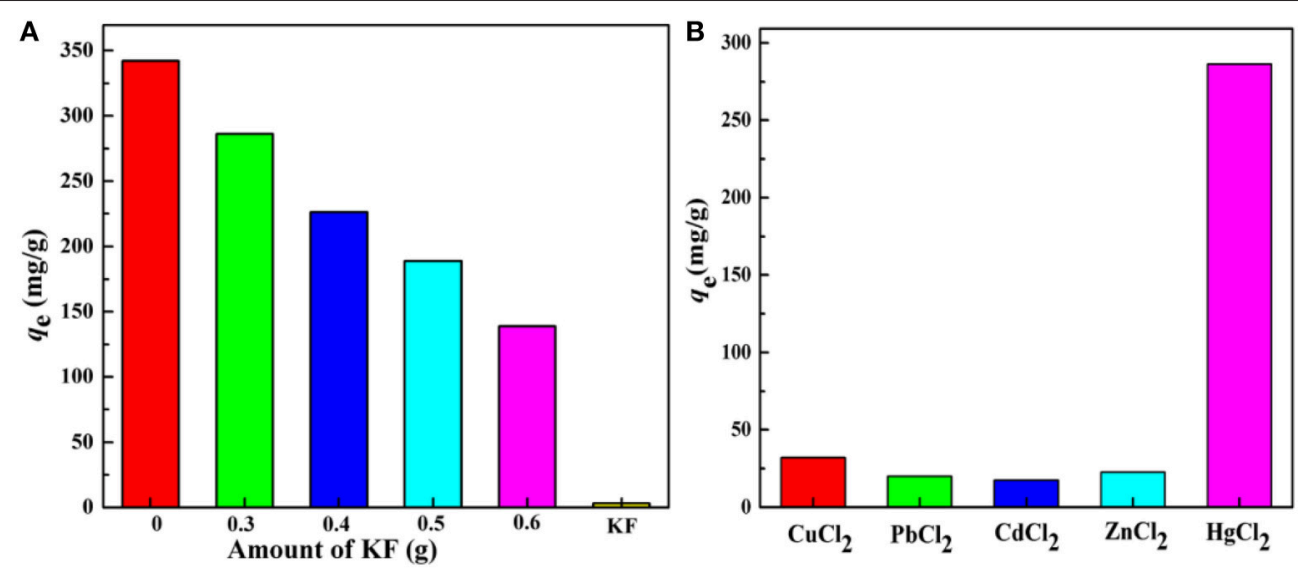

FIGURE 6 | (A) The effect of the amount of KF on adsorption capacity and (B) Adsorption capacities of KF@VIM/EGDMA adsorbents for various divalent heavy metal ions. Adsorption experiments: $C_{0}$ : $300 \mathrm{mg} / \mathrm{L}$; sample dose: $20 \mathrm{mg} / 25 \mathrm{~mL}$; $\mathrm{pH}: 5.5$; temperature: $30^{\circ} \mathrm{C}$; equilibrium time: $120 \mathrm{~min}$. 
the surface of the adsorbent at acidic conditions (Chen et al., 2008). The decreasing concentration of $\mathrm{H}^{+}$which resulted from the $\mathrm{pH}$ increased from 1 to 4 promoted the formation of the mercury-imidazole complex and increased the adsorption capacity of KF@VIM/EGDMA for Hg(II) (Sun et al., 2013). The protonation of imidazole groups in acidic conditions sharply increased the equilibrium $\mathrm{pH}$ of the heavy metal solutions (as shown in inset in Figure 7) and hindered the interaction between heavy metal cations and the adsorbent (Ijagbemi et al., 2010), resulting thus in the reducing number of binding sites available for metal ions uptake. The equilibrium adsorption capacities for $\mathrm{Hg}(\mathrm{II})$ were 262.76 and $653.34 \mathrm{mg} / \mathrm{g}$ when the initial concentration were fixed at 200 and $500 \mathrm{mg} / \mathrm{L}$ at $\mathrm{pH} 6.0$, respectively. According to the results, a series of freshly prepared $\mathrm{HgCl}_{2}$ solutions were directly used without adjusting their

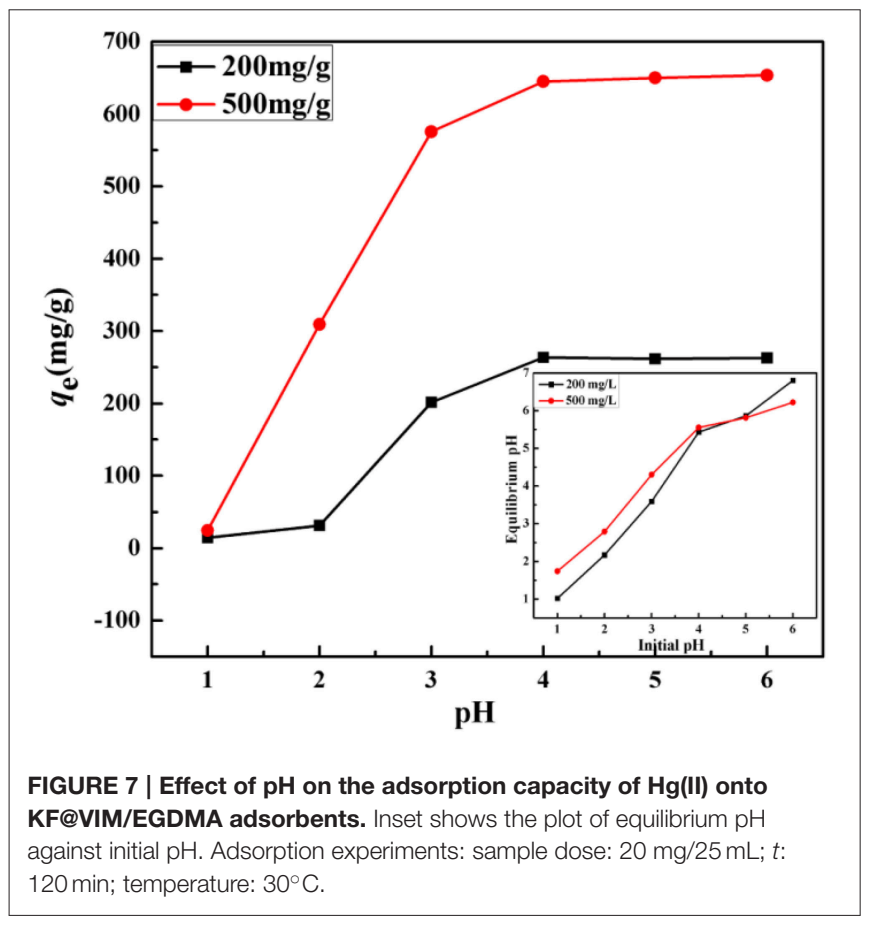

$\mathrm{pH}$-values since the original $\mathrm{pH}$ values for each concentration were all closed to 5.5 .

\section{Adsorption Isotherms}

As the initial concentration of heavy metal ions has a significant influence on the adsorption capacity of the heavy metal ions, the equilibrium isotherms for the adsorption of $\mathrm{Hg}$ (II) by $\mathrm{KF} @ V I M / E G D M A$ at $30^{\circ} \mathrm{C}$ were studied covering a wide range of initial concentrations, as shown in Figure 8A.

The isotherm results reveal the good adsorption capacity of KF@VIM/EGDMA for $\mathrm{Hg}$ (II) with the maximum adsorption capacity to $\mathrm{Hg}$ (II) of $696.87 \mathrm{mg} / \mathrm{g}$ at $30^{\circ} \mathrm{C}$ in aqueous solution. The increasing $\mathrm{Hg}$ (II) concentration would provide the maximum driving force for metal ions to conflict with the mass transfer resistances from the aqueous to adsorbent surface and result in higher probability of collision between the active adsorption sites and $\mathrm{Hg}(\mathrm{II})$, thus allowing the active adsorption sites to be completely used, by which a higher adsorption capacity can be realized.

As shown in Table S2 and Figure 8A, the experimental data could be well fitted by the Langmuir isotherm model $\left(R^{2}=0.9902\right)$ than the Freundlich equation $\left(R^{2}=0.5427\right)$. The Langmuir model assumes that the adsorption sites are energetically equivalent and identical, and only monolayer adsorption occurs in the process (Weber et al., 1991). The adsorption capacities of $\mathrm{Hg}(\mathrm{II})$ onto various adsorbents are listed in Table 2. Compared with other adsorbents, the adsorption capacity of KF@VIM/EGDMA composite for $\mathrm{Hg}(\mathrm{II})$ is quite high. Therefore, KF@VIM/EGDMA is a superior adsorbent that has potential application for the removal of $\mathrm{Hg}(\mathrm{II})$ from polluted water.

\section{Adsorption Kinetics}

The adsorption kinetics of KF@VIM/EGDMA was investigated to determine the adsorption rate which is especially significant for the practical application of an adsorbent. Figure $\mathbf{8 B}$ shows the time dependent of $\mathrm{Hg}$ (II) adsorption on KF@VIM/EGDMA. The adsorption capacity of the adsorbent for $\mathrm{Hg}$ (II) ion shows a rapid increasing with prolonging the contact time, and the adsorption
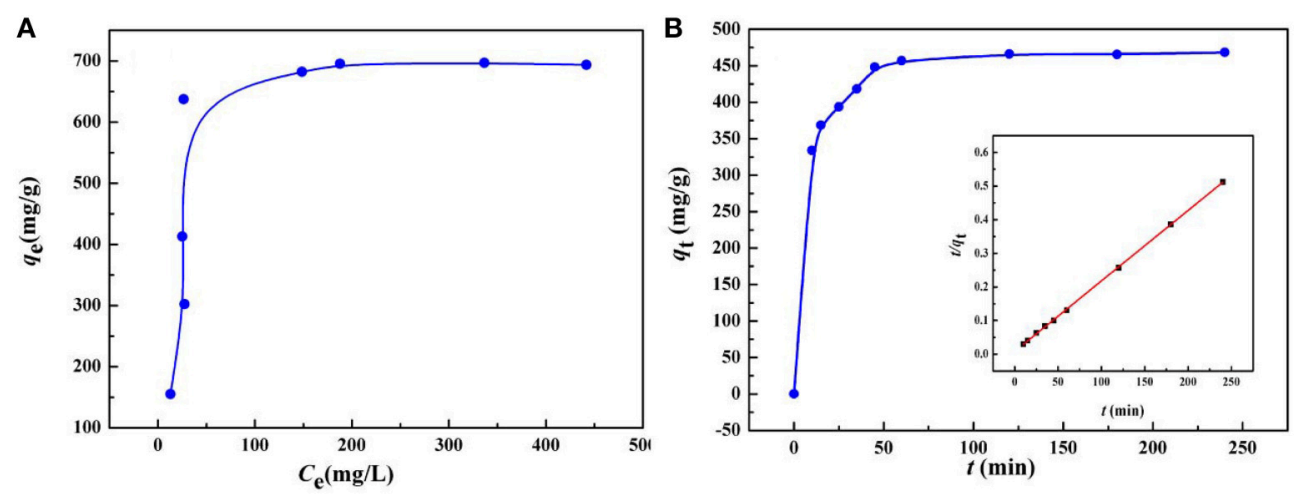

FIGURE 8 | (A) Adsorption isotherm and (B) adsorption kinetics of Hg(II) onto KF@VIM/EGDMA adsorbents. Adsorption experiments: (A) sample dose: 20 mg/25 mL; $\mathrm{pH}: 5.5$; $t$ : $120 \mathrm{~min}$; temperature: $30^{\circ} \mathrm{C}$. (B) $\mathrm{C}_{0}: 400 \mathrm{mg} / \mathrm{L}$; sample dose: $20 \mathrm{mg} / 25 \mathrm{~mL}$; $\mathrm{pH}$ : 5.5 ; temperature: $30^{\circ} \mathrm{C}$. 


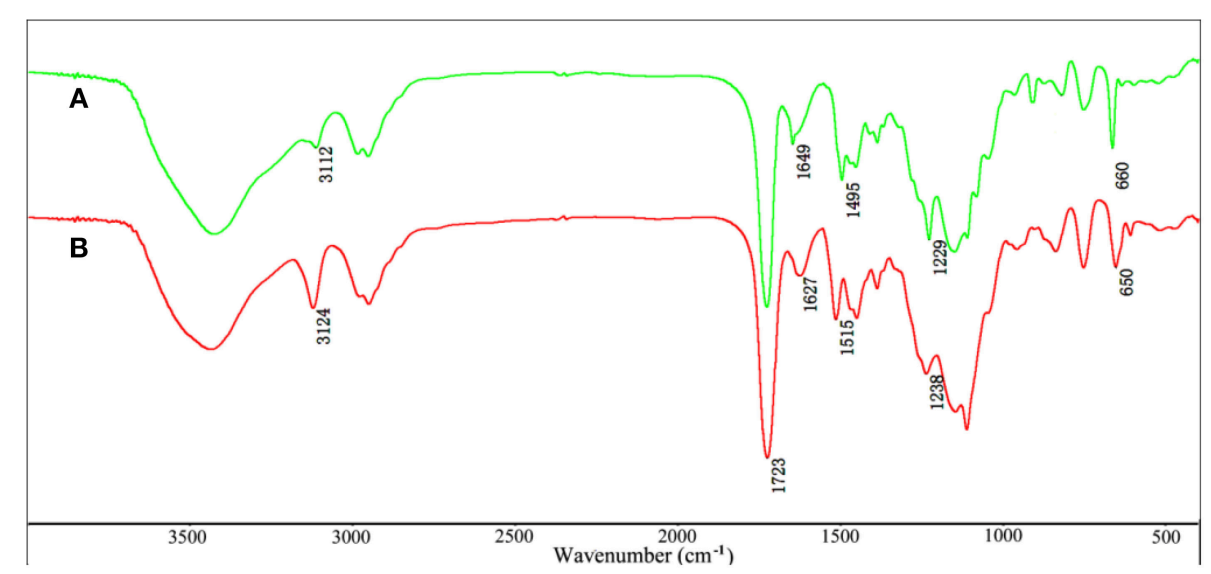

FIGURE 9 | FTIR spectra of KF@VIM/EGDMA before (A) and after (B) $\mathrm{Hg}$ (II) adsorption.

TABLE 2 | Maximum adsorption capacity $\left(q_{\mathrm{m}}\right)$ of various adsorbents for $\mathrm{Hg}$ (II).

\begin{tabular}{|c|c|c|}
\hline Adsorbents & $q_{m}(\mathrm{mg} / \mathrm{g})$ & References \\
\hline Hg-C-TUa & 110 & Monier et al., 2014 \\
\hline poly(vinylalcohol)/poly(vinylimidazole) & 120 & Bessbousse et al., 2010 \\
\hline $\mathrm{TESM}^{\mathrm{b}}$ & 139 & Wang et al., 2013b \\
\hline $\begin{array}{l}\text { poly(1-vinylimidazole)-grafted } \\
\mathrm{Fe}_{3} \mathrm{O}_{4} @ \mathrm{SiO}_{2}\end{array}$ & 346 & Shan et al., 2015 \\
\hline silica-graft-vinyl imidazole & 356 & Sun et al., 2013 \\
\hline $\begin{array}{l}\text { Chitosan-poly(vinylalcohol)/ 10\% } \\
\text { bentonite }\end{array}$ & 455 & Wang et al., 2014 \\
\hline Chitosan-poly(vinylalcohol) & 460 & \\
\hline $\mathrm{EMCR}^{\mathrm{C}}$ & 539 & Zhou et al., 2010 \\
\hline polyaniline/humic acid & 671 & Li et al., 2011 \\
\hline KF@VIM/EGDMA & 697 & This study \\
\hline polyaniline/attapulgite composite & 800 & Cui et al., 2012 \\
\hline $\begin{array}{l}\text { Polypyrrole-reduced grapheme } \\
\text { oxide }\end{array}$ & 980 & Chandra and Kim, 2011 \\
\hline
\end{tabular}

equilibrium was achieved within $50 \mathrm{~min}$. The experiment date indicate a fast adsorption rate of KF@VIM/EGDMA for $\mathrm{Hg}$ (II) removal.

Table S3 indicated that the correlation coefficient values of pseudo-second-order kinetic model $\left(R^{2}=0.9983\right)$ are much better than that of pseudo-first-order kinetic model $\left(R^{2}=0.8015\right)$, suggesting that the adsorption process is in line with the pseudo-second-order kinetics model. Otherwise, the close similarities between experimental adsorption capacity $(468.39 \mathrm{mg} / \mathrm{g})$ and calculated adsorption capacity value $(478.47 \mathrm{mg} / \mathrm{g})$ for $\mathrm{Hg}(\mathrm{II})$ once again proved the better fitting of pseudo-second-order kinetic model in comparison to pseudo-first-order kinetic model. All the information presented in Table S3 signified that the pseudo-second-order model is more appropriate to represent the experimental kinetic data and there is complexation between the $\mathrm{Hg}$ (II) and the adsorbent. The chemical adsorption may be the rate-limiting step (Tapaswi et al., 2014).

\section{Adsorption Mechanism}

Shifts and changes of FTIR peaks would provide powerful evidence to clarify the adsorption mechanism of $\mathrm{Hg}$ (II) onto the functional groups of the as-prepared adsorbent. The chelation between the heavy metal ions and the functional groups will result in the shift of some characteristic absorption bands. The FTIR spectra of KF@VIM/EGDMA before and after $\mathrm{Hg}$ (II) adsorption are shown in Figure 9. After adsorption, the characteristic absorption bands of VIM were all shifted. For examples, the absorption bands at $3112 \mathrm{~cm}^{-1}$ in the spectrum of KF@VIM/EGDMA was shifted to $3124 \mathrm{~cm}^{-1}$ and the intensity became stronger. The peak at 1495 and $1229 \mathrm{~cm}^{-1}$ were shifted to the high wavenumber at 1515 and $1238 \mathrm{~cm}^{-1}$, respectively. The characteristic peaks at 1649 and $660 \mathrm{~cm}^{-1}$ were shifted to the low wavenumber at 1627 and $650 \mathrm{~cm}^{-1}$ after adsorption. There are no obvious change of the strong band at $1723 \mathrm{~cm}^{-1}$ ascribed to the vibration of $\mathrm{C}=\mathrm{O}$ after adsorption. All the information listed above indicated that during the adsorption, midazole groups had been participated in the chelation reaction, while carbonyl group was not involved. The X-ray photoelectron spectroscopy (XPS) was also used to investigate the adsorption mechanism of $\mathrm{Hg}(\mathrm{II})$ onto the KF@VIM/EGDMA. As shown in Figure 10, the appearance of the $\mathrm{Hg}_{4 \mathrm{f}}$ spectrum after the adsorption revealed that the $\mathrm{Hg}(\mathrm{II})$ was specifically adsorbed onto KF@VIM/EGDMA. Two photoelectron peaks detected for $\mathrm{Hg}_{4 \mathrm{f} 7 / 2}(100.78 \mathrm{eV})$ and $\mathrm{Hg}_{4 \mathrm{f5} / 2}(104.88 \mathrm{eV})$ in Figure 10C implied that $\mathrm{Hg}$ (II) existed in a divalent state (Wang et al., 2012). Additionally, as shown in the survey spectra in Figures 10D,E, after adsorption, the binding energy of the imine $\left(>\mathrm{N}_{-}\right)$) nitrogen of the imidazole ring at $398.88 \mathrm{eV}$ (Lázaro Martínez et al., 2011) shifted to $399.18 \mathrm{eV}$, while the amine $(-\mathrm{N}-\mathrm{C}-)$ nitrogen at 400.78 has no obvious change, demonstrating that the imine $(>\mathrm{N}-)$ nitrogen of the imidazole ring mainly chelates with $\mathrm{Hg}$ (II) (Sun 

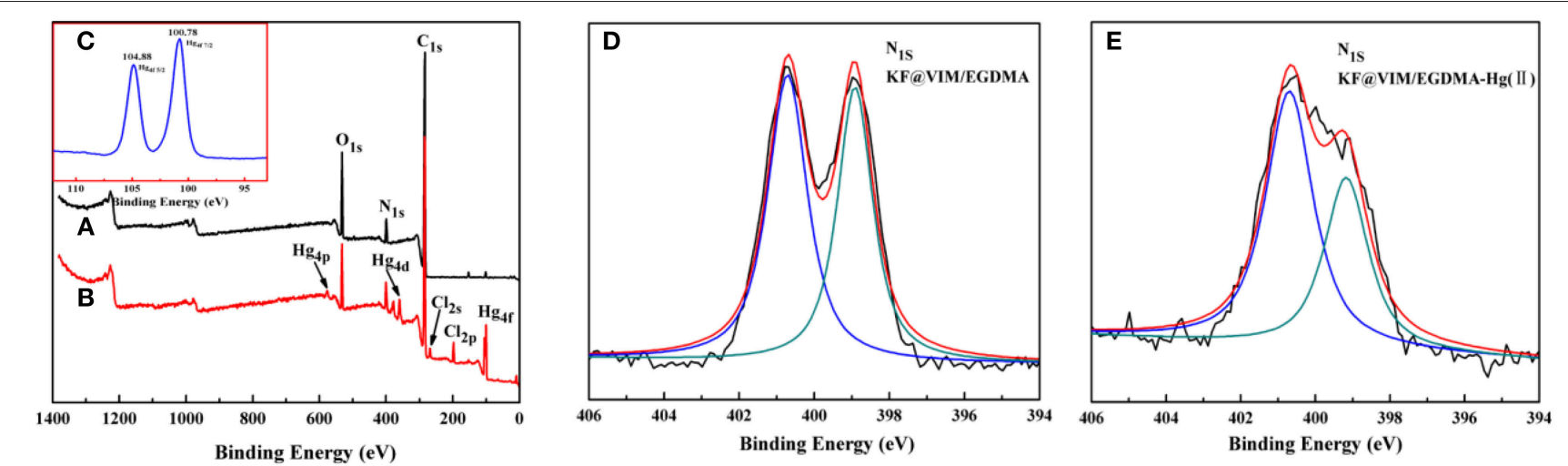

FIGURE 10 | XPS spectra of KF@VIM/EGDMA (A) before $\mathrm{Hg}$ (II) adsorption, (B) after Hg(II) adsorption, (C) $\mathrm{Hg}_{4 f}$, (D) $\mathrm{N}_{1 s}$ of KF@VIM/EGDMA before Hg(II) adsorption and (E) after $\mathrm{Hg}(\mathrm{II})$ adsorption.
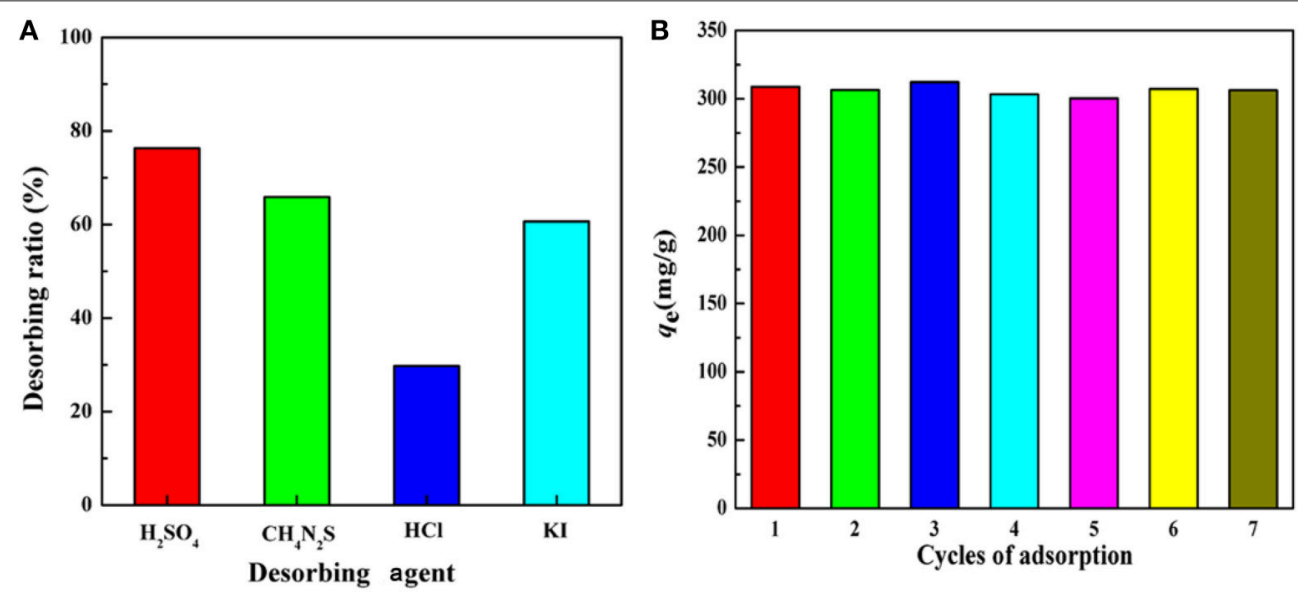

FIGURE 11 | (A) Effect of various desorbing agents on the desorption ability of KF@VIM/EGDMA adsorbent and (B) the reusability of KF@VIM/EGDMA for Hg(II) adsorption. Adsorption experiments: sample dose: $20 \mathrm{mg} / 25 \mathrm{~mL} ; \mathrm{C}_{0}: 300 \mathrm{mg} / \mathrm{L} ; \mathrm{pH}$ : 5.5 ; temperature: $30^{\circ} \mathrm{C}$; equilibrium time: 120 min. Desorption experiments: time: $300 \mathrm{~min}$; temperature: $30^{\circ} \mathrm{C}$.

et al., 2013). The complexation between $\mathrm{Hg}(\mathrm{II})$ and nitrogen atoms transferred the electrons from $\mathrm{Hg}$ to the imidazole rings, and constructed an electron-rich environment for the nitrogen species, decreasing thus the binding energy of $\mathrm{N}_{1 \mathrm{~s}}$ peaks. The probable formation mechanism of mercury-imidazole complex was proposed in Scheme 1.

\section{Desorption and Regeneration Performance}

The desorption studies and the reusability of the KF@VIM/EGDMA were investigated to evaluate the regeneration and reusabilities of the as-prepared adsorbent.

The species of the desorbing agents would significantly affect the desorption efficiency. Thus, the influences of different desorbing agents with the same concentration on desorption efficiency were investigated. According to the results presented in Figure 11 A, $\mathrm{H}_{2} \mathrm{SO}_{4}$ presented the best desorption efficiency among the four desorbing agents. Subsequently, the influences of the concentration of $\mathrm{H}_{2} \mathrm{SO}_{4}$ on desorption efficiency were performed and the results revealed that the desorption ratio showed no significant differences by varying $\mathrm{H}_{2} \mathrm{SO}_{4}$ concentration from 0.1 to $0.9 \mathrm{~mol} / \mathrm{L}$. According to the experiment date, $0.5 \mathrm{~mol} / \mathrm{L} \mathrm{H}_{2} \mathrm{SO}_{4}$ solution was selected to investigate the regeneration and reusability of the adsorbent. As shown in Figure 11B, there appears no significant decrease in the adsorption capacity during the whole adsorption-desorption process, revealing that KF@VIM/EGDMA can be used for multiple cycles, an indication of excellent reusability of the adsorbent for removing $\mathrm{Hg}(\mathrm{II})$ from aqueous solution.

\section{CONCLUSIONS}

A novel adsorbent KF@VIM/EGDMA composite was designed and developed by a facile and green in situ polymerization reaction under mild conditions. The hollow structure and fibrous surface of KF can orientate the polymerization growth, by which a uniform $\mathrm{N}$-containing polymer layer was formed along the KF surface. The as-prepared KF@VIM/EGDMA composite possesses the advantages of excellent adsorption capacity and 
selectivity, and fast adsorption kinetics for $\mathrm{Hg}$ (II) ions, with the adsorption capacity of as high as $697 \mathrm{mg} / \mathrm{g}$ and the adsorption saturation of $45 \mathrm{~min}$. Moreover, the composite based on KF can be separated from the liquid system easily, which is benefit for the recycle of the adsorbent, and the fact of experiment suggested that the as-prepared adsorbent exhibits no obvious retrogress for $\mathrm{Hg}$ (II) removal during several adsorption-desorption process. In conclusion, the KF@VIM/EGDMA can be used as an efficiently and economically viable adsorbent for selective adsorption of $\mathrm{Hg}$ (II) and the development of the composites coated on natural KF by a facile and green method proposed an effective way to utilize natural resources.

\section{AUTHOR CONTRIBUTIONS}

AW: contribute to propose the research idea, design the research programme and revise the research paper. FW: contribute to conducting the research programme and

\section{REFERENCES}

Abdullah, M. A., Rahmah, A. U., and Man, Z. (2010). Physicochemical and sorption characteristics of Malaysian Ceiba pentandra (L.) Gaertn. as a natural oil sorbent. J. Hazard. Mater. 177, 683-691. doi: 10.1016/j.jhazmat.2009.12.085

Afkhami, A., Saber-Tehrani, M., and Bagheri, H. (2010). Simultaneous removal of heavy-metal ions in wastewater samples using nano-alumina modified with 2,4-dinitrophenylhydrazine. J. Hazard. Mater. 181, 836-844. doi: 10.1016/j.jhazmat.2010.05.089

Ali, N., El-Harbawi, M., Jabal, A. A., and Yin, C. Y. (2011). Characteristics and oil sorption effectiveness of kapok fibre, sugarcane bagasse and rice husks: oil removal suitability matrix. Environ. Technol. 33, 481-486. doi: 10.1080/09593330.2011.579185

Alila, S., and Boufi, S. (2009). Removal of organic pollutants from water by modified cellulose fibres. Ind. Crops Prod. 30, 93-104. doi: 10.1016/j.indcrop.2009.02.005

Bessbousse, H., Rhlalou, T., Verchère, J. F., and Lebrun, L. (2010). Mercury removal from wastewater using a poly(vinylalcohol)/poly(vinylimidazole) complexing membrane. Chem. Eng. J. 164, 37-48. doi: 10.1016/j.cej.2010.08.004

Bourikas, K., Vakros, J., Kordulis, C., and Lycourghiotis, A. (2003). Potentiometric mass titrations: experimental and theoretical establishment of a new technique for determining the point of zero charge (PZC) of metal (hydr)oxides. J. Phys. Chem. B 107, 9441-9451. doi: 10.1021/jp035123v

Chandra, V., and Kim, K. S. (2011). Highly selective adsorption of $\mathrm{Hg}^{2+}$ by a polypyrrole-reduced graphene oxide composite. Chem. Commun. 47, 3942-3944. doi: 10.1039/c1cc00005e

Chen, C. Y., Lin, M. S., and Hsu, K. R. (2008). Recovery of Cu(II) and Cd(II) by a chelating resin containing aspartate groups. J. Hazard. Mater. 152, 986-993. doi: 10.1016/j.jhazmat.2007.07.074

Chung, B. Y., Cho, J. Y., Lee, M. H., Wi, S. G., Kim, J. H., Kim, J. S., et al. (2008). Adsorption of heavy metal ions onto chemically oxidized Ceiba pentandra (L.) Gaertn. (Kapok) Fibers. J. Appl. Biol. Chem. 51, 28-35. doi: $10.3839 /$ jabc. 2008.006

Cui, H., Qian, Y., Li, Q., Zhang, Q., and Zhai, J. (2012). Adsorption of aqueous $\mathrm{Hg}$ (II) by a polyaniline/attapulgite composite. Chem. Eng. J. 211-212, 216-223. doi: $10.1016 /$ j.cej.2012.09.057

Duan, C., Zhao, N., Yu, X., Zhang, X., and Xu, J. (2013). Chemically modified kapok fiber for fast adsorption of $\mathrm{Pb}^{2+}, \mathrm{Cd}^{2+}, \mathrm{Cu}^{2+}$ from aqueous solution. Cellulose 20, 849-860. doi: 10.1007/s10570-013-9875-9

El Ghali, A., Baouab, M. H. V., and Roudesli, M. S. (2012). Aminated cotton fibers loaded with copper(II) ions for enhanced pesticide removal performance from water in a laboratory scale batch. Ind. Crops Prod. 39, 139-148. doi: 10.1016/j.indcrop.2012.02.020 writing the paper. Y. Zheng: contribute to conducting the research programme and revising the paper. Y. Zhu: contribute to conducting the research programme as an assistant.

\section{ACKNOWLEDGMENTS}

This work is supported by the National Natural Science Foundation of China (21377135, 21477135 and 51403221), the Fundamental Research Funds for the Central Universities (lzujbky-2015-127) and Youth Innovation Promotion Association, CAS (2015343).

\section{SUPPLEMENTARY MATERIAL}

The Supplementary Material for this article can be found online at: http://journal.frontiersin.org/article/10.3389/fenvs. 2016.00004
Fan, H., Yu, X., Long, Y., Zhang, X., Xiang, H., Duan, C., et al. (2012). Preparation of kapok-polyacrylonitrile core-shell composite microtube and its application as gold nanoparticles carrier. Appl. Surf. Sci. 258, 2876-2882. doi: 10.1016/j.apsusc.2011.10.151

Huang, X., and Lim, T. T. (2006). Performance and mechanism of a hydrophobicoleophilic kapok filter for oil/water separation. Desalination 190, 295-307. doi: 10.1016/j.desal.2005.09.009

Idris, S. A., Harvey, S. R., and Gibson, L. T. (2011). Selective extraction of mercury(II) from water samples using mercapto functionalised-MCM-41 and regeneration of the sorbent using microwave digestion. J. Hazard. Mater. 193, 171-176. doi: 10.1016/j.jhazmat.2011.07.037

Ijagbemi, C. O., Baek, M. H., and Kim, D.-S. (2010). Adsorptive performance of un-calcined sodium exchanged and acid modified montmorillonite for $\mathrm{Ni}^{2+}$ removal: Equilibrium, kinetics, thermodynamics and regeneration studies. J. Hazard. Mater. 174, 746-755. doi: 10.1016/j.jhazmat.2009.09.115

Kampalanonwat, P., and Supaphol, A. P. (2014). The study of competitive adsorption of heavy metal ions from aqueous solution by aminated polyacrylonitrile nanofiber mats. Energy Procedia 56, 142-151. doi: 10.1016/j.egypro.2014.07.142

Kang, P. H., Jeun, J. P., Chung, B. Y., Kim, J. S., and Nho, Y. C. (2007). Preparation and characterization of glycidyl methacrylate (GMA) grafted kapok fiber by using radiation induced-grafting technique. J. Ind. Eng. Chem. 13, 956-958.

Kara, A., Osman, B., Yavuz, H., Beșirli, N., and Denizli, A. (2005). Immobilization of $\alpha$-amylase on $\mathrm{Cu}^{2+}$ chelated poly(ethylene glycol dimethacrylate-n-vinyl imidazole) matrix via adsorption. React. Funct. Polym. 62, 61-68. doi: 10.1016/j.reactfunctpolym.2004.08.008

Keshk, S., Suwinarti, W., and Sameshima, K. (2006). Physicochemical characterization of different treatment sequences on kenaf bast fiber. Carbohyd. Polym. 65, 202-206. doi: 10.1016/j.carbpol.2006.01.005

Kyzas, G. Z., Siafaka, P. I., Lambropoulou, D. A., Lazaridis, N. K., and Bikiaris, D. N. (2014). Poly(itaconic acid)-grafted chitosan adsorbents with different cross-linking for $\mathrm{Pb}(\mathrm{II})$ and $\mathrm{Cd}(\mathrm{II})$ uptake. Langmuir 30, 120-131. doi: 10.1021/la402778x

Lázaro Martínez, J. M., Rodríguez-Castellón, E., Sánchez, R. M. T., Denaday, L. R., Buldain, G. Y., and Campo Dall' Orto, V. (2011). XPS studies on the $\mathrm{Cu}(\mathrm{I}, \mathrm{II})$-polyampholyte heterogeneous catalyst: an insight into its structure and mechanism. J. Mol. Catal. A: Chem. 339, 43-51. doi: 10.1016/j.molcata.2011.02.010

Li, Q., Sun, L., Zhang, Y., Qian, Y., and Zhai, J. (2011). Characteristics of equilibrium, kinetics studies for adsorption of $\mathrm{Hg}(\mathrm{II})$ and $\mathrm{Cr}(\mathrm{VI})$ by polyaniline/humic acid composite. Desalination 266, 188-194. doi: 10.1016/j.desal.2010.08.025 
Lim, T. T., and Huang, X. (2007). Evaluation of kapok (Ceiba pentandra (L.) Gaertn.) as a natural hollow hydrophobic-oleophilic fibrous sorbent for oil spill cleanup. Chemosphere 66, 955-963. doi: 10.1016/j.chemosphere.2006.05.062

Liu, X., Zhang, J., Guo, X., Wang, S., and Wu, S. (2012a). Core-shell $\alpha-\mathrm{Fe}_{2} \mathrm{O}_{3} @$ $\mathrm{SnO}_{2} / \mathrm{Au}$ hybrid structures and their enhanced gas sensing properties. RSC Adv. 2, 1650-1655. doi: 10.1039/C1RA00811K

Liu, Y., Wang, J., Zheng, Y., and Wang, A. (2012b). Adsorption of methylene blue by kapok fiber treated by sodium chlorite optimized with response surface methodology. Chem. Eng. J. 184, 248-255. doi: 10.1016/j.cej.2012.01.049

Monier, M., Kenawy, I. M., and Hashem, M. A. (2014). Synthesis and characterization of selective thiourea modified $\mathrm{Hg}$ (II) ion-imprinted cellulosic cotton fibers. Carbohyd. Polym. 106, 49-59. doi: 10.1016/j.carbpol.2014.01.074

Oo, C. W., Kassim, M. J., and Pizzi., A. (2009). Characterization and performance of Rhizophora apiculata mangrove polyflavonoid tannins in the adsorption of copper (II) and lead (II). Ind. Crops Prod. 30, 152-161 doi: 10.1016/j.indcrop.2009.03.002

Prachayawarakorn, J., Chaiwatyothin, S., Mueangta, S., and Hanchana, A. (2013). Effect of jute and kapok fibers on properties of thermoplastic cassava starch composites. Mater. Design 47, 309-315. doi: 10.1016/j.matdes.2012.12.012

Shan, C., Ma, Z., Tong, M., and Ni, J. (2015). Removal of $\mathrm{Hg}(\mathrm{II})$ by poly(1vinylimidazole)-grafted $\mathrm{Fe}_{3} \mathrm{O}_{4} @ \mathrm{SiO}_{2}$ magnetic nanoparticles. Water Res. 69, 252-260. doi: 10.1016/j.watres.2014.11.030

Shen, C., Wang, Y., Xu, J., and Luo, G. (2013). Chitosan supported on porous glass beads as a new green adsorbent for heavy metal recovery. Chem. Eng. J. 229, 217-224. doi: 10.1016/j.cej.2013.06.003

Strelko V. Jr., Malik, D. J., and Streat, M. (2002). Characterisation of the surface of oxidised carbon adsorbents. Carbon 40, 95-104. doi: 10.1016/S00086223(01)00082-3

Sun, J., Chen, Z., Ge, M., Xu, L., and Zhai, M. (2013). Selective adsorption of Hg(II) by $\gamma$-radiation synthesized silica-graft-vinyl imidazole adsorbent. J. Hazard. Mater. 244-245, 94-101. doi: 10.1016/j.jhazmat.2012.11.043

Talu, M., Demiroğlu, E. U., Yurdakul, S̨., and Badoğlu, S. (2015). FTIR, Raman and NMR spectroscopic and DFT theoretical studies on poly(N-vinylimidazole). Spectrochim. Acta A 134, 267-275. doi: 10.1016/j.saa.2014.06.101

Tapaswi, P. K., Moorthy, M. S., Park, S. S., and Ha, C.-S. (2014). Fast, selective adsorption of $\mathrm{Cu}^{2+}$ from aqueous mixed metal ions solution using 1,4,7triazacyclononane modified SBA-15 silica adsorbent (SBA-TACN). J. Solid State Chem. 211, 191-199. doi: 10.1016/j.jssc.2013.12.028

Uğuzdoğan, E., Denkbaş, E. B., Öztürk, E., Tuncel, S. A., and Kabasakal, O.S. (2009). Preparation and characterization of polyethyleneglycolmethacrylate (PEGMA)-co-vinylimidazole (VI) microspheres to use in heavy metal removal. J. Hazard. Mater. 162, 1073-1080. doi: 10.1016/j.jhazmat.2008.05.145
Wang, J., Zheng, Y., and Wang, A. (2013a). Coated kapok fiber for removal of spilled oil. Mar. Pollut. Bull. 69, 91-96. doi: 10.1016/j.marpolbul.2013. 01.007

Wang, S., Wei, M., and Huang, Y. (2013b). Biosorption of multifold toxic heavy metal ions from aqueous water onto food residue eggshell membrane functionalized with ammonium thioglycolate. J. Agric. Food Chem. 61, 4988-4996. doi: 10.1021/jf4003939

Wang, X., Yang, L., Zhang, J., Wang, C., and Li, Q. (2014). Preparation and characterization of chitosan-poly(vinyl alcohol)/bentonite nanocomposites for adsorption of $\mathrm{Hg}$ (II) ions. Chem. Eng. J. 251, 404-412. doi: 10.1016/j.cej.2014.04.089

Wang, Y., Yang, H., Pschenitza, M., Niessner, R., Li, Y., Knopp, D., et al. (2012). Highly sensitive and specific determination of mercury(II) ion in water, food and cosmetic samples with an ELISA based on a novel monoclonal antibody. Anal. Bioanal. Chem. 403, 2519-2528. doi: 10.1007/s00216-0126052-1

Weber, W. J., McGinley, P. M., and Katz, L. E. (1991). Sorption phenomena in subsurface systems: Concepts, models and effects on contaminant fate and transport. Water Res. 25, 499-528. doi: 10.1016/0043-1354(91)90125-A

Xia, Y., Lu, X., and Zhu, H. (2013). Natural silk fibroin/polyaniline (core/shell) coaxial fiber: Fabrication and application for cell proliferation. Compos. Sci. Technol. 77, 37-41. doi: 10.1016/j.compscitech.2013.01.008

Zheng, Y., Liu, Y., and Wang, A. (2012). Kapok fiber oriented polyaniline for removal of sulfonated dyes. Ind. Eng. Chem. Res. 51, 10079-10087. doi: 10.1021/ie300246m

Zheng, Y., Zhu, Y., and Wang, A. (2014). Kapok fiber structure-oriented polyallylthiourea: Efficient adsorptive reduction for $\mathrm{Au}(\mathrm{III})$ for catalytic application. Polymer 55, 5211-5217. doi: 10.1016/j.polymer.2014.08.040

Zhou, L., Liu, Z., Liu, J., and Huang, Q. (2010). Adsorption of $\mathrm{Hg}$ (II) from aqueous solution by ethylenediamine-modified magnetic crosslinking chitosan microspheres. Desalination 258, 41-47. doi: 10.1016/j.desal.2010.03.051

Conflict of Interest Statement: The authors declare that the research was conducted in the absence of any commercial or financial relationships that could be construed as a potential conflict of interest.

Copyright (c) 2016 Wang, Zheng, Zhu and Wang. This is an open-access article distributed under the terms of the Creative Commons Attribution License (CC BY). The use, distribution or reproduction in other forums is permitted, provided the original author(s) or licensor are credited and that the original publication in this journal is cited, in accordance with accepted academic practice. No use, distribution or reproduction is permitted which does not comply with these terms. 